\title{
Which Factors of Economic Freedom Matter the Most - Case Study on the Example of Emerging Economics
}

\author{
Vakhtang Chkareuli ${ }^{1}$ \\ ${ }^{1} \mathrm{PhD}$ Candidate in Economics, Tbilisi State University, Department of Macroeconomics, Tbilisi, \\ Georgia
}

\begin{abstract}
Nowadays, we live in the most prosperous era of humanity, what to a large extent is caused by advancing economic freedom. Policies that promote economic freedom through different channels, create an environment in which people are encouraged and trusted to develop practical solutions to the economic and social challenges.
\end{abstract}

Economic freedom is critical to generating broader-based economic growth that brings more opportunities for a greater number of people to work, produce more and save for the future. Ensuring greater economic freedom is directly related to preserving and enhancing dynamic upward mobility.

Economic freedom index, which is yearly published by Heritage Foundation is based on the key aspects of free-market economy. It gathers them into four main categories: rule of law, government size, regulatory efficiency and open markets. All of the four above mentioned categories cover different topics and indexes like property rights, tax burden, government spending, labor freedom, trade freedom etc.

In this paper, we are going to assess those ingredients of economic freedom index and analyse which of them influence the country's economy the most. Empirical study will be made on the example of emerging economies.

Keywords: Economic Freedom Index; Economic Development; 